ARGONNE NATIONAL LABORATORY

9700 South Cass Avenue, Argonne, Illinois 60439

\title{
ANALYSIS OF THE SWELLING BEHAVIOR OF U-ALLOYS*
}

J. Rest, G. L. Hofman, and K. L. Coffey

Argonne National Laboratory

U.S.A

and

RECEIVED

I. Konovalov and A. Maslov

NOY 041997

Bochvar Institute

Russia

OSTI

October, 1997

Government purposes.

*Work supported by U.S. Department of Energy, Office of Arms Control and Nonproliferation, under Contract W-31-109-Eng-38.

Presented at the $20^{\text {th }}$ International Meeting on Reduced Enrichment for Research and Test Reactors, Jackson Hole, WY., October 5-11, 1997 


\section{DISCLAIMER}

This report was prepared as an account of work sponsored by an agency of the United States Government. Neither the United States Government nor any agency thereof, nor any of their employees, makes any warranty, express or implied, or assumes any legal liability or responsibility for the accuracy, completeness, or usefulness of any information, apparatus, product, or process disclosed, or represents that its use would not infringe privately owned rights. Reference herein to any specific commercial product, process, or service by trade name, trademark, manufacturer, or otherwise does not necessarily constitute or imply its endorsement, recommendation, or favoring by the United States Government or any agency thereof. The views and opinions of authors expressed herein do not necessarily state or reflect those of the United States Government or any agency thereof. 


\section{DISCLAMIER}

Portions of this document may be illegible in electronic image produets. Imsges are produced from the best available original docoment. 


\title{
ANALYSIS OF THE SWELLING BEHAVIOR OF U-ALLOYS
}

J. Rest, G. L. Hofman, and K. L. Coffey

Argonne National Laboratory

U.S.A

and

\section{Konovalov and A. Maslov \\ Bochvar Institute \\ Russia}

\begin{abstract}
Available data on two alloys from the EBR-II driver fuel development program have been utilized in the construction and validation of mechanistic models aimed at elucidating swelling mechanisms in high density uranium alloys. Swelling predictions are made under ATR conditions for U-10Mo fuels, currently under irradiation in the ATR, and for U-10Zr.
\end{abstract}

\section{Introduction}

Detailed postirradiation data on uranium alloys irradiated at the relatively low temperatures of interest to the RERTR program are not available to guide us in the selection of suitable high density LEU fuel prospects. We have, thus far, relied on low-burnup swelling data and metallurgical experience to select basically two groups of alloys for our test matrix. One group consists of metastable $\gamma \mathrm{U}$ (bcc) alloys - chiefly U-Mo, while the other group comprises several two-phase alloys of $\mathrm{U}-\mathrm{ZrNb}$ in which the two phases ( $\alpha \mathrm{U}$ and $\delta \mathrm{ZrNb}$ ) exist in a very fine lamellar microstructure. The selection of these, basically very different, alloys has its roots in different interpretations of the controlling swelling mechanisms taken by Russian and U.S groups that are jointly involved in the development of high density LEU fuels.

For the swelling modeling work presented in this paper, we have utilized available data on two alloys from the EBR-II driver fuel development. One alloy, U-5 w/o fs (basically U-3Ru$2 \mathrm{Mo}$, fs=fissium), albeit not a stabilized single-phase $\gamma$ alloy, does contain the $\gamma \mathrm{U}$ phase as one of its three phases. A typical example of the microstructure of U-5fs taken from the midplane region of the EBR-II core is shown in Fig. 1. The irradiation temperature of this sample was $\sim 600^{\circ} \mathrm{C}$ and the burnup $0.8 \%$ of all $\mathrm{U}$ atoms. The apparently randomly oriented grain structure is very fine, consisting of $\alpha \mathrm{U}$ (white), $\mathrm{U}_{2} \mathrm{Ru}$ (light gray) an intermetallic phase, and $\mathrm{U}_{2} \mathrm{Mo}$ (dark gray) the ordered form $\gamma \mathrm{U}$-Mo. The order-disorder temperature is around $600^{\circ} \mathrm{C}$, but at the prevailing high fission rate in EBR-II the phase is likely disordered at any temperature. It is of interest to note that 


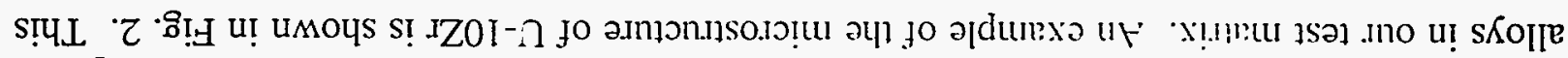

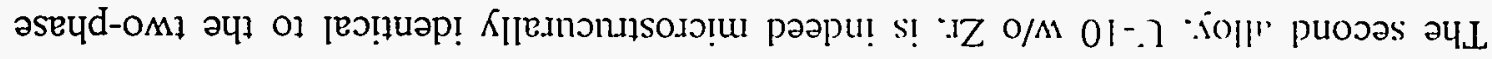

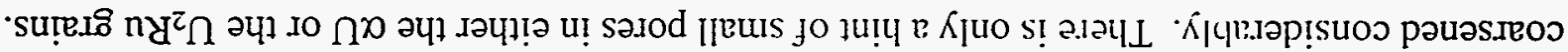

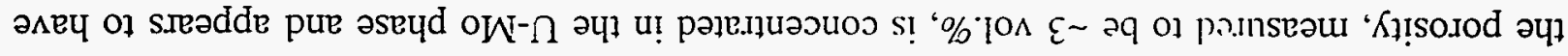

-ว.I0ว

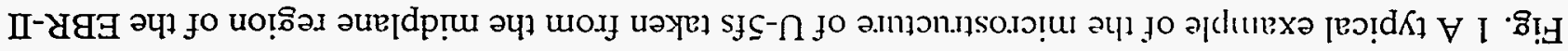

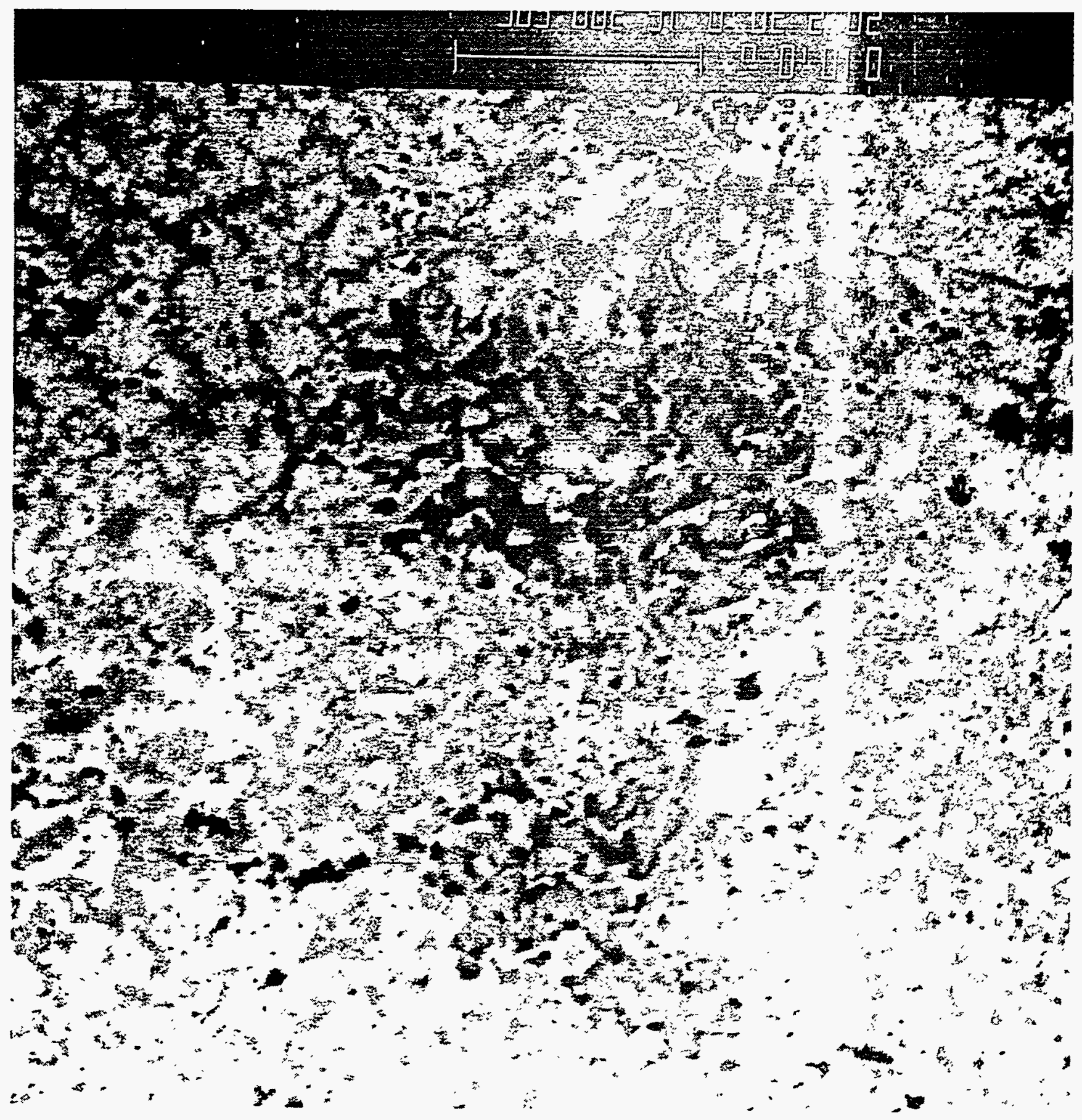


structure is clearly lamellar and consists of $\alpha \mathrm{U}$ and $\delta \mathrm{UZr}_{2}$. The $\delta$ phase, similar to the $\mathrm{U}_{2} \mathrm{Mo}$ phase in that they both are ordered forms of $\gamma \mathrm{U}\left(\mathrm{Mo}, \mathrm{Zr}\right.$ solid solution), forms at around $600^{\circ} \mathrm{C}$.
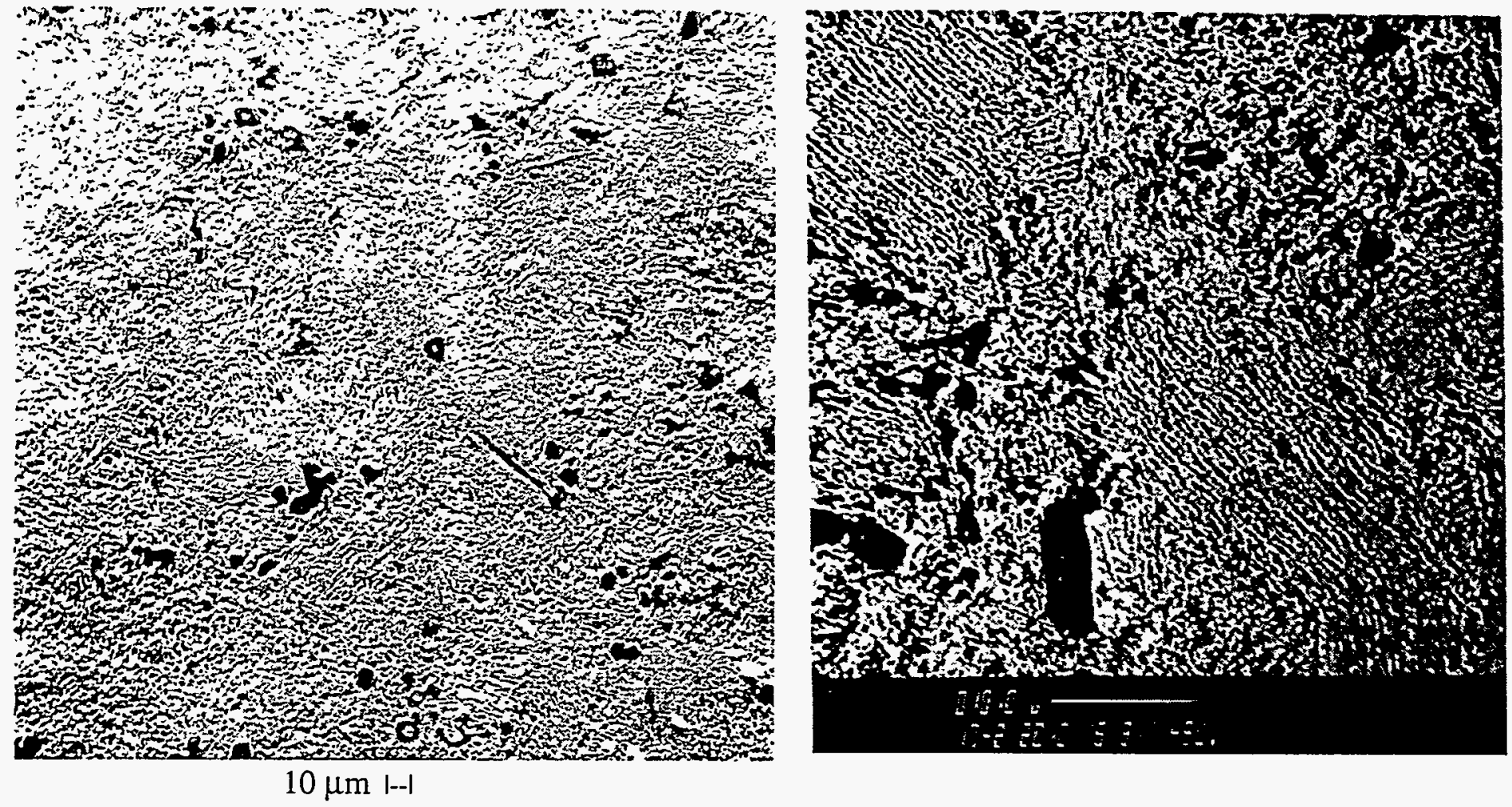

Fig. 2 An example of the microstructure of $U-10 \mathrm{Zr}$

The $\gamma$ phase is also likely to disorder as a result of fissioning. The porosity in the U-10Zr sample consists of two distinct features. Porosity has formed in the $\mathrm{UZr}_{2}$ lamellar phase as in the $\mathrm{U}_{2} \mathrm{Mo}$ phase, but in addition much larger irregular porosity has formed at the junction of cells of misaligned lamella. This cellular microstructure is much coarser than the grain structure in U$5 f s$, and it is surmised that the cells act in a manner similar to $\alpha U$ grains, i.e., directional growth in the $\alpha \mathrm{U}$ results in tearing at the cell boundaries. The overall swelling of $U-10 \mathrm{Zr}$ is much larger -- $30 \%$ volume increase at $0.9 \%$ burnup versus $5 \%$ for $U-5 f$ at $0.8 \%$ burnup.

Detailed image analysis was performed on the scanning electron micrographs -shown in Figs. 1 and 2, as well as on micrographs from other locations on the fuel elements. Porosity, grain size, and phase morphology were quantified for use in the present modeling work.

Another interesting observation was made during postirradiation heating tests carried out under various pressures. The compression of U-5fs was completely reversible, whereas a considerable fraction of the as-irradiated volume increase in $\mathrm{U}-10 \mathrm{Zr}$ was permanently lost during compression. This indicates that the porosity in U-5fs consists of gas bubbles and that a fraction of the porosity in U-10Zr consists of either voids or under-pressurized bubbles. These are likely the large tear-like pores at the cell boundaries. 


\section{Modeling of U-10Zr Swelling Behavior by a Vacancy Mechanism}

According to the vacancy swelling model (VACS), the irradiation period is divided into three stages, which are characterized as follows:

- Interstitials have the greatest mobility and form a dislocation structure during the initial stages of irradiation (stage 1).

- Vacancies have intermediate mobility and cause void nucleation and growth during the subsequent stage of irradiation (stage 2).

- Fission-gas atoms have the lowest mobility and smallest effect on materials behavior-- important only when the first and second stages are finished (stage 3).

In order to describe these three stages, the traditional equations for irradiationproduced point defects (vacancies and interstitials) are used. The first stage is possible when an equilibrium state is not achieved, i.e. during initial stages of irradiation. For dislocation loop nucleation, a homogeneous nucleation mechanism and capillary approach were chosen.

For the second stage, the dislocation structure is assumed to be constant during the evolution of the porosity structure. For describing pore nucleation, a formal approach based on calculating vacancy excess (supersaturation), not taking into account a particular mechanism of void nucleation (homogeneous and/or heterogeneous nucleation, e.g., on specific sites or in thermal spikes), is used. The distributions of sub-critical nuclei and above-critical size pores are considered (elaborated approach).

According to this elaborated approach, the size of critical nuclei increases as a function of irradiation time. As the critical pore size increases in value, a point is reached where the vacancy flux required to support the sub-critical nuclei distribution becomes greater than the vacancy excess, and pore nucleation is stopped.

The third stage consists of the evolution of the pore structure due to vacancy and fission-gas atom flow into the pores. As in stage 2, the calculation of the point defect flux to pores utilizes the equations for steady-state. The rate of vacancy evaporation from pores is defined by taking into account the internal pressure of gas atoms in a pore.

The lamellar structure in $\mathrm{U}-10 \mathrm{Zr}$ has a rigid crystallographic orientation, and it is reasonable to assume that there is a strong bond between the lamellae, and thus, the boundary will reflect or appear transparent to point defects. Thus, the phase boundaries are not considered in the VACS analysis-- the pores in the lamellar structure nucleate and grow in the body of the grain. For evaluation of the validity of the VACS model, the multiphase U-10Zr structure was homogenized and additive physical parameters were used.

Computed results for alloy swelling using VACS and comparison with experimental results are shown in Fig. 3. Diametric swelling of the fuel slug was calculated as 

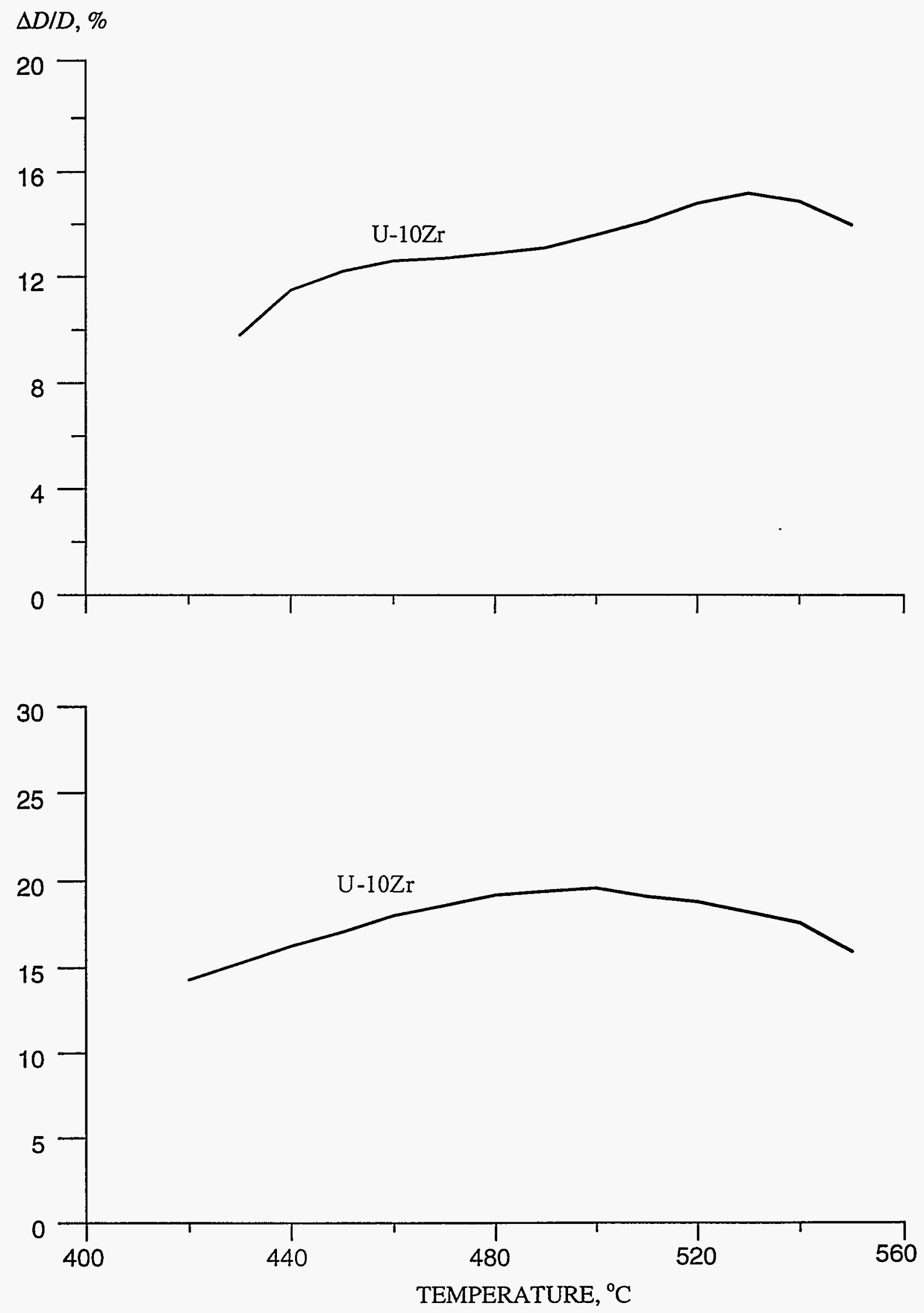

Fig.3. Experimental (above, [1,2]) and VACS-calculated (below) diametric swelling at 0.9 at.\% burnup under EBR-II conditions. 
$3 \Delta D / D=\Delta V / V$, taking into account an average radial fuel temperature gradient of $130^{\circ} \mathrm{C}$.

The VACS-calculated pore radii were compared with pore radii calculated for equilibrium gas bubbles without vacancy supersaturation. It was established that at a low burnup of less than 1 at.\%, U-10Zr contains pores having a radius 2-3 times bigger than that calculated for stable gas bubbles. Thus, at this stage, pure vacancy swelling is the operative swelling mechanism. With increasing burnup, the difference between radii decreases, and after (10-20) at.\% burnup the swelling may be described as pure gas swelling. The calculated average diameter of pores after 0.9 at.\% burnup is 0.4 microns and the pore density is about $3 \times 10^{13} \mathrm{~cm}^{-3}$.

The above calculations are consistent with the postirradiation compression and expansion tests described in Section 1. Irradiated U-10Zr alloy under applied stress and elevated temperature irreversibly decreases its volume, and in this case we have sintering of vacancy (in contrast to gas-bubble) porosity.

The calculated swelling behavior of the U-10Zr alloy under ATR conditions is shown in Fig.4. Computed results for temperatures of $150-200^{\circ} \mathrm{C}$, fission rate of $3.5 \times 10^{14} \mathrm{~cm}^{-3} \mathrm{~s}^{-1}$ and burnup of $5 \times 10^{21}$ fissions $/ \mathrm{cm}^{3}$ are: dislocation density $1-3 \times 10^{11} \mathrm{~cm}^{-2}$, pore density of 2$4 \times 10^{15} \mathrm{~cm}^{-3}$ and average pore diameter of $0.03-0.15$ microns. The results shown in Fig. 4 demonstrate that the swelling behavior of $\mathrm{U}-10 \mathrm{Zr}$ is a very strong function of temperature. Uncertainties in operating temperature, as well as the open question as to the extent of grainboundary tearing in $\mathrm{U}-10 \mathrm{Zr}$ at these low temperatures, suggest that vacancy swelling in the U$10 \mathrm{Zr}$ alloy under ATR conditions may be a limiting factor in fuel performance.

\section{Analysis of Swelling in Uranium Fissium and in U-Mo Alloys}

During irradiation of uranium fission under EBR-II conditions, $\mathrm{U}_{2}$ Mo particles transform to the disordered gamma phase. As discussed in Section 1, this phase is expected to be present in the U-Mo alloys in the ATR due to the high fission rate. In the absence of data for U-Mo alloys irradiated at low temperature, an analysis of swelling behavior of $\mathrm{U}_{2} \mathrm{Mo}$ particles in U-5fs enables the construction of a physically based mechanistic model, CAVITY, that can be subsequently applied to an analysis of swelling under ATR conditions. In addition, validation of the model against low-burnup, high-temperature irradiation data for U-14Mo provides additional verification that the physics of swelling in the alloy has been reasonably described. Models based on VACS and CAVITY will eventually be incorporated into the DART code [3].

A striking observation of the cavity population in the $\mathrm{U}_{2} \mathrm{Mo}$ particles is that the majority of the cavities occupy a significant volume fraction within the particle and appear to be associated with the $\mathrm{U}_{2} \mathrm{Mo}-\mathrm{L}_{2} \mathrm{Ru}$ boundary. A much smaller number of cavities not apparently associated with a boundary are also observed. The results of the postirradiation compression and expansion tests indicate that the swelling in the U-5fs is primarily gas driven. Thus, the interpretation of the observations made here is that fission-gas bubbles primarily nucleated on the $\mathrm{U}_{2} \mathrm{Mo}-\mathrm{U}_{2} \mathrm{Ru}$ boundaries grow into the $\mathrm{U}_{2} \mathrm{Mo}$ particle where they link up with cavities nucleated within the particle resulting in the observed distribution. Bubbles do not appear at $0.8 \%$ burnup within the $\mathrm{U}_{2} \mathrm{Ru}$ phase due, presumably, to substantially lower diffusivites than 


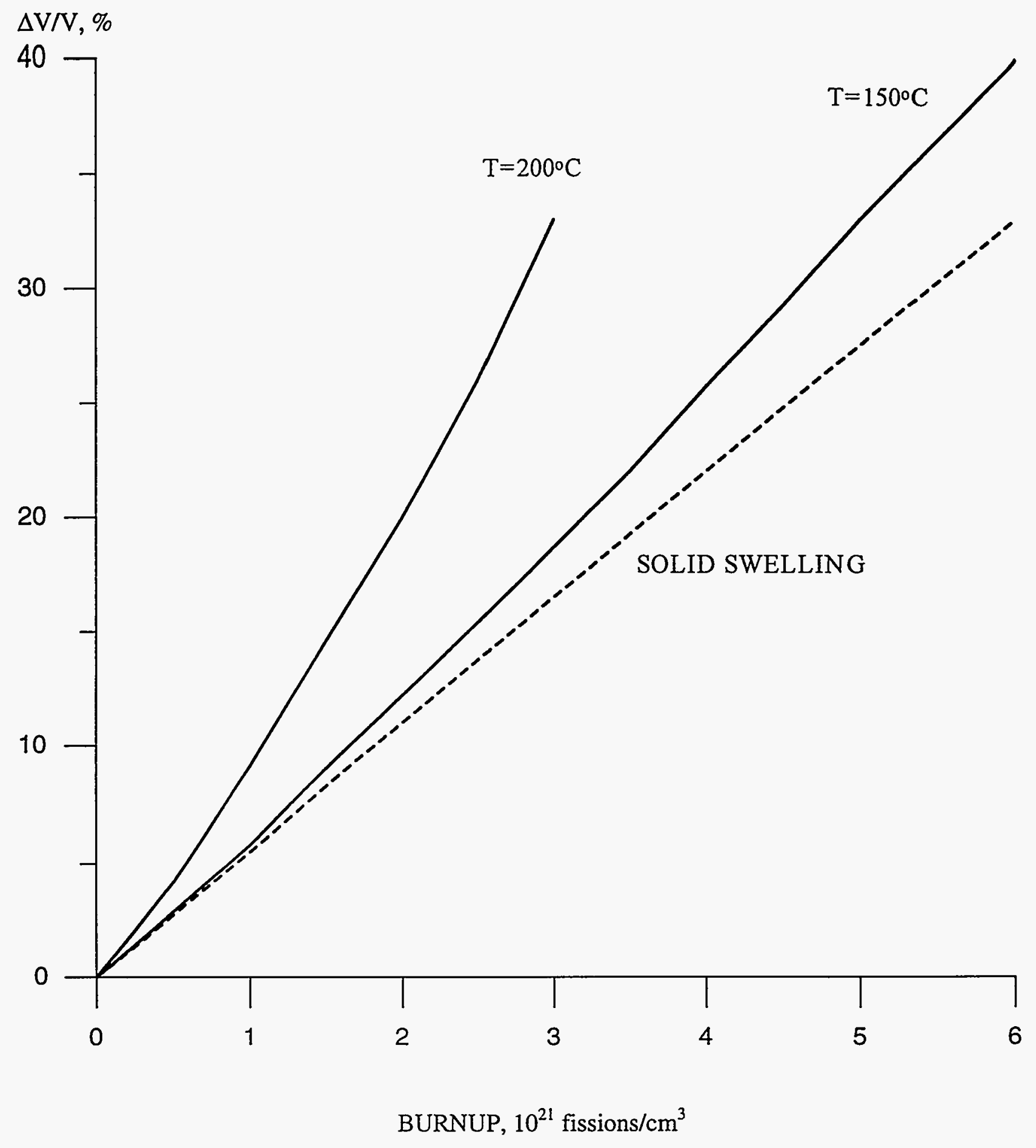

Fig.4. Calculated swelling of U-10Zr alloy for ATR conditions. 
occur in the disordered gamma-uranium phase (small bubbles appear within the $\mathrm{U}_{2} \mathrm{Ru}$ at $8 \%$ burnup whereas catastrophic swelling occurs within the $\mathrm{U}_{2} \mathrm{Mo}$ particles).

Irradiation-produced defects and fission-gas atoms are generated within the $\mathrm{U}_{2} \mathrm{Mo}$ particle and in the surrounding alpha-uranium material (for purpose of this discussion, the $\mathrm{U}_{2} \mathrm{Ru}$ phase is ignored). Cavity nucleation in the $\mathrm{U}-5 \mathrm{fs}$ occurs if several vacancies (or a vacancy cluster) are in the near vicinity of interacting gas atoms. Irradiation-induced resolution can cause bubble destruction (or shrinkage) within the fuel matrix, but is assumed to be ineffective on the boundary due to a high value of the boundary sink strength (long effective gas-atom recapture distance). Dislocations within the fuel compete with the growing cavities for irradiation-produced defects and, thus, influence the swelling behavior of the cavities. Fission gas and irradiation-produced defects diffuse to the boundary, reducing their availability within the matrix while providing a source term for cavity nucleation and growth on the boundary. The $\mathrm{U}_{2} \mathrm{Mo}-\mathrm{U}_{2} \mathrm{Ru}$ boundary receives fission gas and defect source terms from both the alpha-uranium and the $\mathrm{U}_{2} \mathrm{Mo}$ particle matrix. If the gas-atom flux to the cavity is sufficiently high compared to the vacancy flux, the excess pressure is greater or equal to zero and gas bubbles are calculated. Otherwise, underpressurized bubbles, or voids are calculated. It is assumed that the cavities within the $\mathrm{U}_{2}$ Mo particle and on the boundary diffuse by a volume-diffusion mechanism. Bubble interaction and coalescence results in a coarsening of the gas-bubble distribution.

Existing irradiation data have been obtained from relatively high-temperature irradiations $\left(500-800^{\circ} \mathrm{C}\right)$ to very low burnups $(<1$ at.\%). The uranium-molybdenum alloy fuels irradiated in the ATR as part of the advanced alloy test matrix are expected to see temperatures $<200^{\circ} \mathrm{C}$. At these relatively low temperatures, irradiation-enhanced diffusion will be the dominant mechanism of gas-atom diffusion. On the other hand, at $500-800^{\circ} \mathrm{C}$, thermal diffusion will be the dominant mechanism of gas atom diffusion.

Irradiation-enhanced gas-atom diffusion coefficients were derived based on studies of structural changes taking place in two-phase uranium-molybdenum alloys under the action of neutron irradiation [4]. This assumption is reasonable if the irradiation-induced gas-atom diffusion mechanism is similar to the irradiation-induced phase mixing mechanism. In addition, if point-defect behavior in the uranium-molybdenum alloy is dominated by the presence of sinks, the gas-atom diffusion coefficient will be independent of temperature and linearly dependent on fission rate. This dependence has been observed in other types of nuclear fuels such as the oxides, mixed oxides, carbides, and nitrides. It is exactly this dependence that is predicted by a model based on the irradiation-induced phase-mixing formulation of Reference 4. In addition, the value of the gas-atom diffusion coefficient obtained in this manner lies within the scatter of the measured diffusion coefficients in oxides, mixed oxides, carbides, and nitrides [5].

Figure 5 shows the calculated swelling in uranium fissium at 450 and $600^{\circ} \mathrm{C}$ irradiated in EBR- II as a function of fission density. The calculated excess pressure in the grainboundary cavities is positive and, thus, the cavities are predicted to be fission gas bubbles. This result is consistent with the full recovery of swelling measured in the postirradiation compression and expansion tests on uranium fissium. Interlinkage of the boundary bubbles with the matrix cavities results in a gas bubble within the matrix in contact with the boundary. 
The calculated bubble size, density, and swelling are consistent with the measured values reported in Section 1.

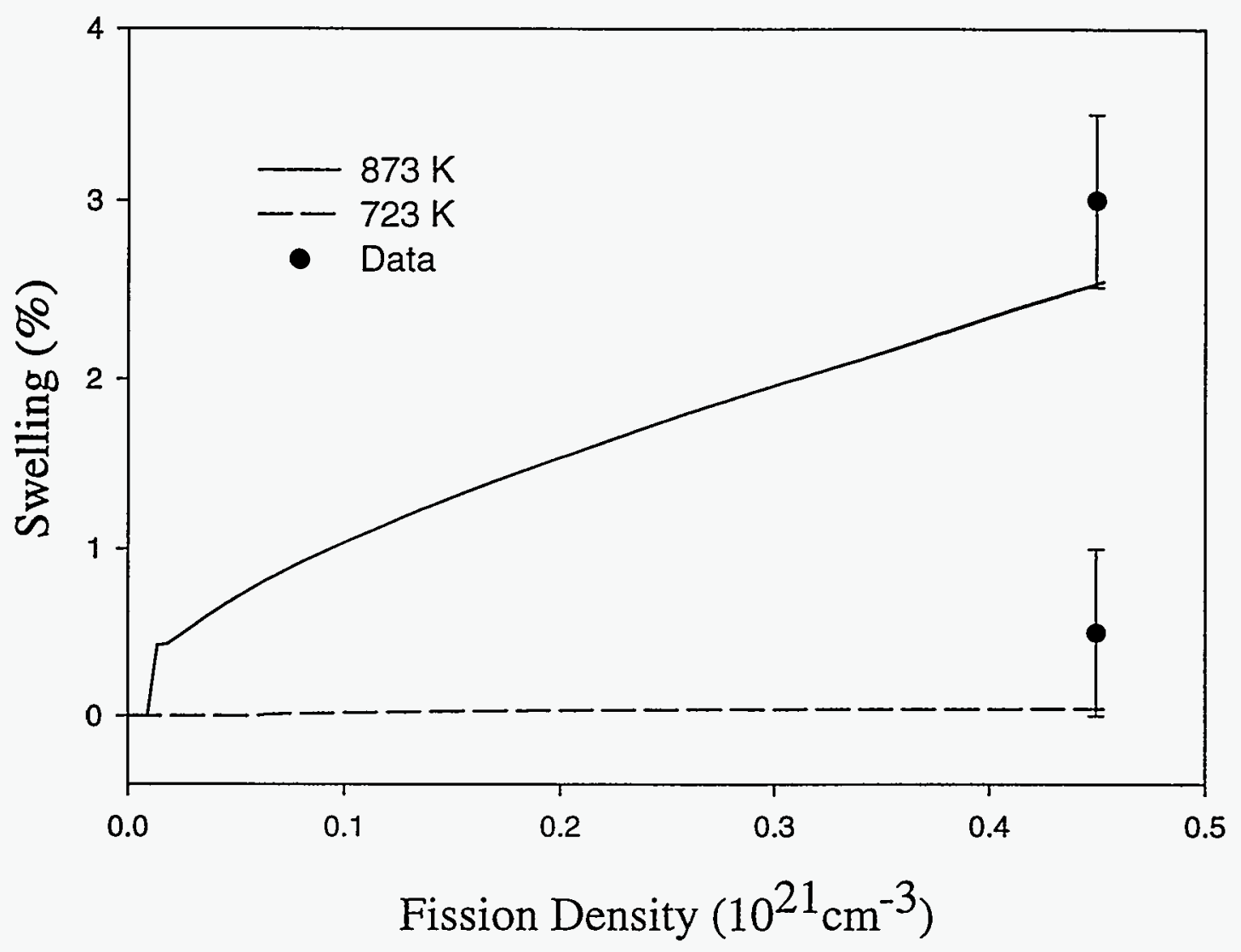

Fig. 5. Calculated swelling in U-5fs irradiated in EBR-11 as a function of fission density.

Calculations were also performed for U-14 wt\% Mo irradiated at $800^{\circ} \mathrm{C}$ to 0.2 at.\% burnup. The results of the calculations indicate that fission-gas bubbles form primarily in the matrix (the material has a relatively large grain size of about $10 \mu \mathrm{m})$. The calculated bubble density $\left(\sim 2 \times 10^{12} \mathrm{~cm}^{-3}\right)$, size $(\sim 0.05 \mu \mathrm{m}$ average radius), and swelling $(\sim 0.1 \%)$ at 0.2 at.\% burnup are consistent with reported observations $\left(\sim 1 \times 10^{13} \mathrm{~cm}^{-3}\right)$, size $(\sim 0.025 \mu \mathrm{m}$ average radius), and swelling $(\sim 0.1 \%)$ in this material [6]. Calculations made to burnups $>1$ at.\% indicate that the bubbles become substantially overpressurized. The internal stresses produced by this overpressurized bubble distribution is a driving force for fuel creep, increased vacancy fluxes, and the subsequent catastrophic failure of the material. 
Figure 6 shows calculated results using CAVITY for fission-gas bubble swelling for U-10Mo irradiated at $150^{\circ} \mathrm{C}$ under ATR conditions. The calculated excess pressure is positive, thus supporting a gas-driven swelling prediction as compared to bias-driven growth processes. The cavities become equilibrium gas bubbles due to the relatively high flux of gas atoms (via irradiation-enhanced diffusion) into the cavities as compared to vacancies (relatively low mobility and concentration). The relative absence of neutral sinks within the alloy, as well as lower gas-atom diffusivities (thermal diffusion is operative at $600^{\circ} \mathrm{C}$ whereas irradiation-

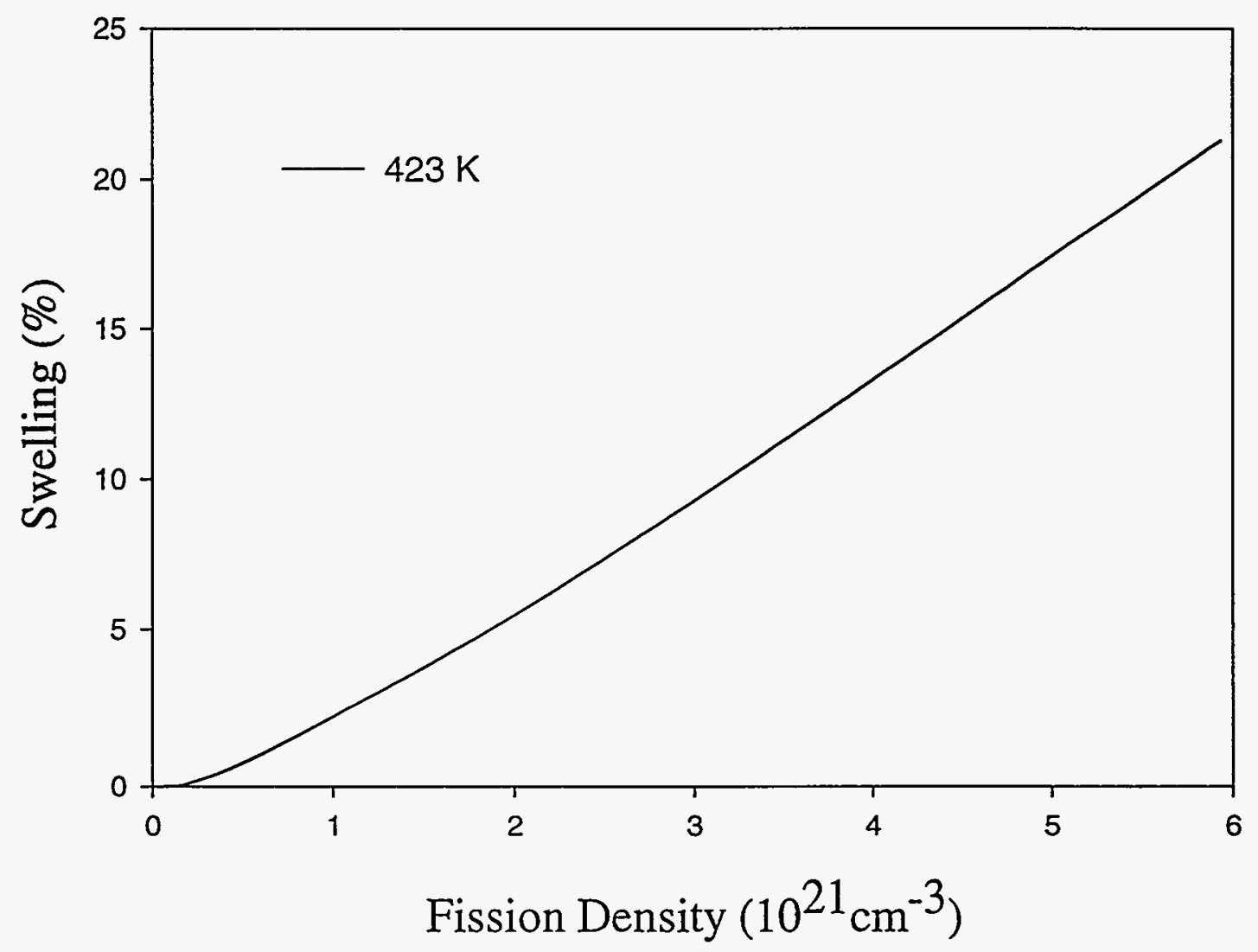

Fig. 6. Calculated results for fission-gas bubble swelling for U-10 Mo irradiated at $150^{\circ} \mathrm{C}$ under ATR conditions.

enhanced diffusion dominates at $150^{\circ} \mathrm{C}$ ) results in the formation of a relatively high density of small fission gas bubbles within the alloy during irradiation. 
The swelling predictions shown in Figure 6 indicate that about $20 \%$ gas bubble swelling is predicted to occur at about $80 \% 235 \mathrm{U}$ burnup. Solid fission-product swelling will result in about a $30 \%$ volume change at this burnup. The predicted total fission-product swelling in the LEU U-10Mo is, then, about $50 \%$ at $80 \% 235$ Uburnup. Thus, the swelling behavior of the alloy is similar to that observed for $\mathrm{U}_{3} \mathrm{Si}_{2}$ dispersion fuels. This result suggests that fission-product swelling in the U-10Mo alloy under ATR conditions will not be a limiting factor in fuel performance.

\section{Conclusions}

Available data on two alloys (U-10Zr, U-5fs) from the EBR-II driver fuel development program, as well as high-temperature, low-burnup data of U-14Mo, have been utilized in the construction and validation of mechanistic models aimed at elucidating swelling mechanisms in high-density uranium alloys. Other swelling mechanisms, such as the matrix aluminum-fuel interaction and grain-boundary tearing, have not been considered in these analyses. The VACS analysis treats pure vacancy swelling, whereas CAVITY requires the presence of fission-gas atoms as well as vacancies for cavity nucleation. CAVITY has the capability of calculating bias-driven swelling (i.e., vacancy) and gas-driven swelling, as well as the transition from one swelling mechanism to the other. In addition, CAVITY treats both interand intragranular swelling processes. Key materials properties used in CAVITY (e.g., defect migration and formation energies for the different alloys as well as the dislocation densities) were derived based on the VACS formalism.

VACS-calculated results demonstrate that the swelling behavior of $\mathrm{U}-10 \mathrm{Zr}$ is a very strong function of temperature. Uncertainties in operating temperature, as well as the open question as to the extent of grain-boundary tearing in U-10Zr during low temperature irradiation, suggest that vacancy swelling in the U-10Zr alloy under ATR conditions may be a limiting factor in fuel performance. CAVITY-calculated swelling behavior of the U-10Mo alloy under ATR conditions is similar to that observed for $\mathrm{U}_{3} \mathrm{Si}_{2}$ dispersion fuels. This result suggests that fission-product swelling in the U-10Mo alloy under ATR conditions will not be a limiting factor in fuel performance 


\section{References}

1. G. Hofman, R. Pahl, C.Lahm and D. Porter. Met. Trans. 21/A (1990) p. 517

2. J. Rest. J. Nucl. Mat. 207 (1993) p.192.

3. J. Rest, "The DART Dispersion Analysis Research Tool: A Mechanistic Model for Predicting Fission-Product-Induced Swelling of Aluminum Dispersion Fuels," ANL-95/36, Argonne National Laboratory (August, 1995).

4. S. T. Konobeevsky, K. P. Dubrovin, B. M. Levitsky, L. D. Panteleev, and N. F. Pravdyuk, Second Geneva Conference paper 232, 1958.

5. Hj. Matzke, in Diffusion Processes in Nuclear Materials, R.P. Agarwala, editor, Elsevier Science Publishers B.V. (1992) 9-69.

6. G. W. Greenwood, J. Nucl. Mater., 6 (1962) 26-34. 